\title{
HYGINO AMANAJÁS E SUA PRODUÇÃO DE LIVROS DE LEITURAS ESCOLARES PARA O ENSINO PRIMÁRIO: FRAGMENTOS DA HISTÓRIA DA LEITURA NO PARÁ
}

Francisca Izabel Pereira Maciel Faculdade de Educação - Universidade Federal de Minas Gerais/UFMG franciscaceale@gmail.com

Kátia Gardênia Henrique da Rocha Universidade Federal de Ouro Preto katiagardenia2@gmail.com

\section{RESUMO}

Este texto traz fragmentos da História da Leitura no Estado do Pará ao desvelar o estudo historiográfico realizado sobre a trajetória intelectual e profissional de Hygino Amanajás (1852-1921), cujo nome é inserido nos quadros da História do Estado do Pará como personalidade política, envolvido com a Educação e autor dos livros escolares: Noções de Educação Civica e Alma e Coração. Tem-se ainda, apresentados elementos acerca do processo de produção, divulgação e circulação dessas obras. Esses elementos fornecem indícios que possibilitam, mesmo que de forma incipiente, conhecer aspectos sobre a história da leitura. Dentre esses elementos destaca-se a influência do livro Cuore, de Edmundo de Amicis, na produção do livro Alma e Coração.

Palavras-chave: Livros escolares. Cultura Escolar. História da Leitura.

\section{HYGINO AMANAJÁS AND HIS PRODUCTION SCHOOL READING BOOKS FOR PRIMARY SCHOOL: FRAGMENTS OF THE READING HISTORY IN PARÁ}

\begin{abstract}
This text contains fragments of the Reading History of the state of Pará as it unveils the accomplished hitoriographic study about Hygino Amanajás (1852-1921) intelectual and professional trajectory, wich name is inserted in the history of the state of Pará as a political personality, engaged in Education and author of the school books: Noções de Educação Civica and Alma e Coração. It also contains elements regarding the production process, propagation and circulation of those works. Those elements provide indications to enable even if incipient, know aspects of the history of reading. Among those elements, stands out the influence of the Edmundo de Amicis book Cuore in the production of the book Alma $e$ Coração.
\end{abstract}

Keywords: School books. School Culture. History of Reading. 


\section{A EDUCAÇÃO NO PARÁ: O ENSINO PRIMÁRIO EM DESTAQUE ${ }^{1}$}

Durante o período colonial, na Capitania do Grão Pará ${ }^{2}$, como nas demais Capitanias da Colônia, as iniciativas educacionais recebiam apenas a influência dos jesuítas e de outras ordens religiosas. $\mathrm{O}$ modelo de ensino era pautado na catequese e instrução dos gentios, nesse período, foram criadas escolas de primeiras letras, que propagavam os ideais religiosos.

As referências que permanecem na historiografia da educação brasileira sobre as escolas no período do império retratam um cenário de precariedade e atraso, a estrutura física dos estabelecimentos de ensino era considerada inadequada e comprometedora da qualidade do ensino. Após o Ato Adicional de 1834 que criou sistemas de ensino nas províncias, com o intuito de descentralizar as iniciativas educacionais, o sistema educacional nacional continuou precário, os investimentos destinados às províncias eram insuficientes para o custeio da instrução pública. Nesse contexto, foram criadas escolas particulares que ofereciam ensino primário para atender aos filhos das famílias abastadas. A instrução pública recebeu, de forma paulatina, investimentos financeiros e intelectuais. Os reflexos desses investimentos puderam ser percebidos nas estatísticas escolares que apontam a ampliação do número de escolas na província. Nos períodos de 1837 a 1839, havia 33 escolas; de 1840 a 1888, o número saltou para 159 escolas e, em 1889, havia 577 escolas no Estado.

Na província do Grão Pará, as décadas finais do século XIX e iniciais do século XX foram marcadas por mudanças políticas, culturais, econômicas, sociais. Por volta de 1880, com o surgimento do Ciclo da Borracha ${ }^{3}$, a economia da província estava em alta e atraiu muitos imigrantes. A prosperidade era tão grande que Belém passou por uma transformação urbanística e ficou conhecida como a "Petite Paris". Foram erguidos suntuosos prédios públicos e casas residenciais, o centro da cidade foi intensamente arborizado com mangueiras trazidas da Índia, o comércio local expandiu-se com a inauguração de grandes lojas, bancos, casas seguradoras e firmas dos mais diversos segmentos.

\footnotetext{
${ }^{1}$ Agradecemos a todas as pessoas que contribuíram para efetivação deste trabalho investigativo, dentre essas, destacamos: Maricilde Oliveira Coelho, Ediza Maria dos Santos Morais, aos funcionários do Centro Cultural e Turístico (CENTUR), em especial, da Biblioteca Pública Arthur Vianna em Belém-Pará, pela presteza no fornecimento de informações e dados para esta pesquisa.

${ }^{2}$ Hoje, Estado do Pará da República Federativa do Brasil.

${ }^{3}$ O Ciclo da Borracha foi um momento importante da história econômica e social do Brasil, relacionado com a extração e comercialização da borracha. Esse ciclo viveu seu auge entre 1879 e 1912, depois experimentou uma sobrevida entre 1942 e 1945, durante a II Guerra Mundial (1939-1945).

${ }^{4}$ Antônio Lemos era o intendente da província do Grão Pará na época da reforma urbanística em que a cidade de Belém ficou conhecida como a pequena Paris.
} 
A influência da Europa podia ser facilmente reconhecida nas ruas de Belém, em busca da modernidade europeia, símbolos da civilidade como escolas, associações literárias e cafés foram criados. Essa expansão foi retrada em jornais da época, como o jornal Folha do Norte, de 28 de fevereiro de 1898, p.1, que apontava o surgimento de instituições como

\begin{abstract}
a Escola Normal, O Lyceu Paraense, [...] tendo além do curso integral de Ciências e Letras, o Comercial e o de Agrimensura, a Escola de Belas Artes, o Conservatório de Música, O Lyceu Benjamin Constant; o Colégio do Amparo, o Instituto de Educandos e Orfelinato Paraense. Há além disso um avultado número de casas particulares de instrução primária e secundária entre as quais salientam-se no sexo masculino o Atheneu Paraense, o Colégio Minerva, o Colégio Pará e Amazonas, o Seminário do Carmo e o Colégio da Imaculada Conceição; e no sexo feminino o Colégio e Asilo e Santo Antonio, e os colégios de Santa Luzia, o Antunes e o Progresso. Na arena literária: [...] a Mina Literária [...] Acabam de fundar-se o Grêmio Paraense e a Sociedade Médico-Farmacêutica Paraense.
\end{abstract}

As luxuosas construções eram motivo de orgulho da população, divulgadas em jornais, revistas e livros, retratavam o progresso. Na contracapa do livro Noções de Educação Civica, de Hygino Amanajás, é reproduzida a fotografia do Theatro da Paz, fundado em Belém nesse período áureo do Ciclo da Borracha. E no sistema de Ensino? Quais seriam as influências europeias?

O progresso propiciado com o início da "era da borracha" possibilitou o desenvolvimento da industrialização e da urbanização. Juntamente com esses fatores, outros elementos, como o advento da República, o fim da escravidão, a imigração, demandaram uma nova organização social presumida mais moderna e civilizada.

Destarte, no final do século XIX, logo após o advento da República, o Estado do Pará encontrava-se inserido em um movimento no qual a educação da população era considerada um elemento propulsor, capaz de viabilizar o processo de evolução da sociedade paraense. A supervalorização da Educação como instrumento estimulador da modernidade, civilidade e unidade nacional era um dos pressupostos republicanos ${ }^{5}$.

No Estado do Pará, a partir de 1890, no que tange à Educação, no governo de Justo Chermont, a instrução pública passou por transformações significativas que visavam a prosperidade nacional. Medidas adotadas nesse período favoreciam a uniformidade e o caráter patriótico do ensino. Dentre essas, estavam a reorganização do ensino primário; a determinação de que o diretor geral da instrução pública expedisse um regimento interno, com programas de ensino meticulosos, prevendo horário e instruções pedagógicas para sua

\footnotetext{
${ }^{5}$ Em cada Estado do país, de acordo com sua singularidade, foram despendidos esforços na tentativa de materializar esse pressuposto, os estudos de Veiga (2000) e Carvalho (1989) trazem informações sobre esforços despendidos, no campo educacional nos Estados de Minas Gerais e São Paulo.
} 
execução. $\mathrm{O}$ ensino primário foi dividido em elementar e integral. $\mathrm{O}$ nível elementar com duração de três anos, o nível integral foi dividido em três cursos: elementar, médio e superior, com duração de seis anos.

Nessa atmosfera de mudanças, José Verissimo Dias de Mattos assumiu a direção geral da instrução pública e, em sua primeira reunião com o professorado, encerrou o seu discurso com as seguintes palavras:

Pelo regulamento de 7 de maio, pela instituição do Conselho Superior, dos conselhos escolares, das garantias de que tem cercado o professorado, estorvos que tem posto ao favoritismo no provimento das cadeiras, é muito o que já deve a instrucção publica do Pará ao dr. Justo Chermont, mas é muito mais o que temos todos o direito de reclamar e esperar do seu patriotismo, da sua illustração e do seu amor por esta terra.

Com essa declaração, tem-se sinalizada a relevância das medidas adotadas pelo governo para a instrução pública. O regulamento da instrução publica de 7 de maio de 1890 serviu de base para as demais reformas realizadas ao longo das primeiras décadas da República no Estado do Pará. Nele estavam materializadas as normas e condutas necessárias ao bom andamento da instrução primária no Estado do Pará.

Ao comentar sobre a evolução da escola primária no Pará, no início do regime republicano, Cardoso (1915) declarou que a partir do regulamento de 1890, aconteceram muitas reformas no campo educacional, apesar de alguns percalços, a escola primária transformou-se, com uma nova orientação, mais pedagógica e proveitosa. No entanto, o verdadeiro problema educativo não se consistia em reformar o ensino primário e sim reorganizá-lo com melhores métodos e possibilitar a melhoria da qualidade da formação dos professores.

Mesmo com os esforços e investimentos financeiros e intelectuais destinados à melhoria da instrução pública, os resultados positivos alcançados foram poucos significativos, como apontou Alexandre Vaz Tavares ${ }^{6}$ em 1894:

O estado intellectual das escolas primárias, sinto profundamente em dize-lo, ainda
não é animador, devido a circumstancias multiplas e complexas. Uma dellas era a
grande variedade de compendios acceitos em cada escola para o estudo de uma
mesma materia. A segunda causa do estorvo ao progredimento do nosso ensino
primário é a falta de livros para classe dos pauperrimos. A terceira causa capital,
dentre os motivos que tem contribuido entre nós, para o embaraço na marcha da
instrucção primaria, é a falta que ainda temos de mobilia escolares de varios
generos.

${ }^{6}$ Relatório do Diretor geral da instrução publica ao governo em 1894. 
O educador Alexandre Vaz Tavares, ao denunciar a precariedade das escolas primária do Pará, enfatiza dados importantes como a falta de uniformidade na instrução pública e a limitação dos investimentos financeiros que não atendia às necessidades do aparelhamento escolar demandado pelo modelo de escola adotado. Acredita-se que o governo, nesse período, utilizava, como estratégia para minimizar essa situação, a distribuição gratuita de livros escolares. No Annuario de Belém, são apresentadas informações sobre a estatística escolar de 31 de dezembro de 1893, de acordo com esses dados, o governo distribuiu gratuitamente 26.385 obras escolares, cujos títulos e nomes dos autores são listados a seguir: Primeiros livros de leitura, Augusto Pinheiro; Lições de Cousas, E. Zaluar; Grammatica Portugueza, João Ribeiro; Terceiro Livro de Leitura, Dr. Freitas; Coração, Edmundo de Amicis; História Pátria, Moreira Pinto; Geographia Primaria, Dr. Novaes; Geometria Elementar, A. da Gama; Arithmetica, Antonio Trajano.

Em relação ao ensino primário, percebe-se que um marco importante foi a reforma de 1890, que serviu de base para as demais reformas do ensino. Essas tinham por objetivos melhorar o que já estava instituído, suprir lacunas existentes e adequar o projeto educativo de maneira que fosse viabilizada a formação do cidadão republicano.

Dentre as medidas adotadas, era considerada imprescindível a criação de grupos escolares, essa necessidade foi apontada antes mesmo do advento da República, como pode ser conferida nas falas de Joaquim Pedro Corrêa de Freitas e Raymundo Nina Ribeiro7: "Acho conveniente que se construam annualmente duas casas de escolas, começando pela capital, para chegar depois ás localidades do interior, segundo a sua importancia" (FREITAS citado por CARDOSO, 1915, p. 69). Para Raymundo Nina Ribeiro, a construção de grupos escolares representava muito para o ensino primário:

O grande dispendio que faz a provincia com o ensino publico, as melhores reformas que emprehender o mais habil professorado que crear, tudo será disperdicio incompleto e improficuo, se não for acompanhado da resolução de, desde já, se dar principio às construcções dos edificios escolares" (RIBEIRO citado por CARDOSO, 1915, p. 69).

Mesmo com sua importância reconhecida, no processo de ensino aprendizagem do ensino primário, o primeiro grupo escolar a ser instalado em Belém foi criado pelo decreto $\mathrm{n}^{\circ}$ 935 de 7 de Janeiro de 1901, sob a denominação de José Verissimo. E no interior do Estado,

\footnotetext{
${ }^{7}$ Diretores gerais da Instrução Pública Paraense, o primeiro em 1881 e o segundo em 1889.
} 
foi o da cidade de Alenquer, criado pelo decreto $n^{\circ} 722$ de 10 de Julho de $1899^{8}$. Em que medida, ocorreu essa ampliação do número grupos escolares prevista nos discursos oficiais?

Medidas que abarcaram a formação de professores, ampliação da inspeção escolar, ampliação do aparelhamento escolar e outras fizeram parte das reformas operadas no ensino primário no Estado do Pará, no entanto, o mapeamento e aprofundamento sobre esse assunto não fez parte desta investigação.

Em relação ao ensino primário no Estado do Pará, dados estatísticos apresentados por Cardoso (1915) apontaram uma crescente evolução desse nível de ensino na primeira década do século XX. Em 1912, havia, na capital, 7 grupos escolares com 3.578 alunos, escolas isoladas com 515 alunos; no interior, 29 grupos escolares com 5.381, 92 escolas isoladas com 3.733 alunos; nos Institutos do Estado, 1.147; perfizeram 14.354 alunos matriculados. O número de alunos matriculados podia não corresponder ao número de alunos frequentes às aulas, entretanto, a quantidade de crianças matriculadas era significativa naquele contexto histórico.

Nesse cenário de ampliação do ensino primário, Hygino Amanajás escreveu seus livros escolares.

\footnotetext{
${ }^{8}$ Dados coletados em CARDOSO, 1915, p. 69.
} 


\section{HYGINO AMANAJÁS E SUAS OBRAS 9}

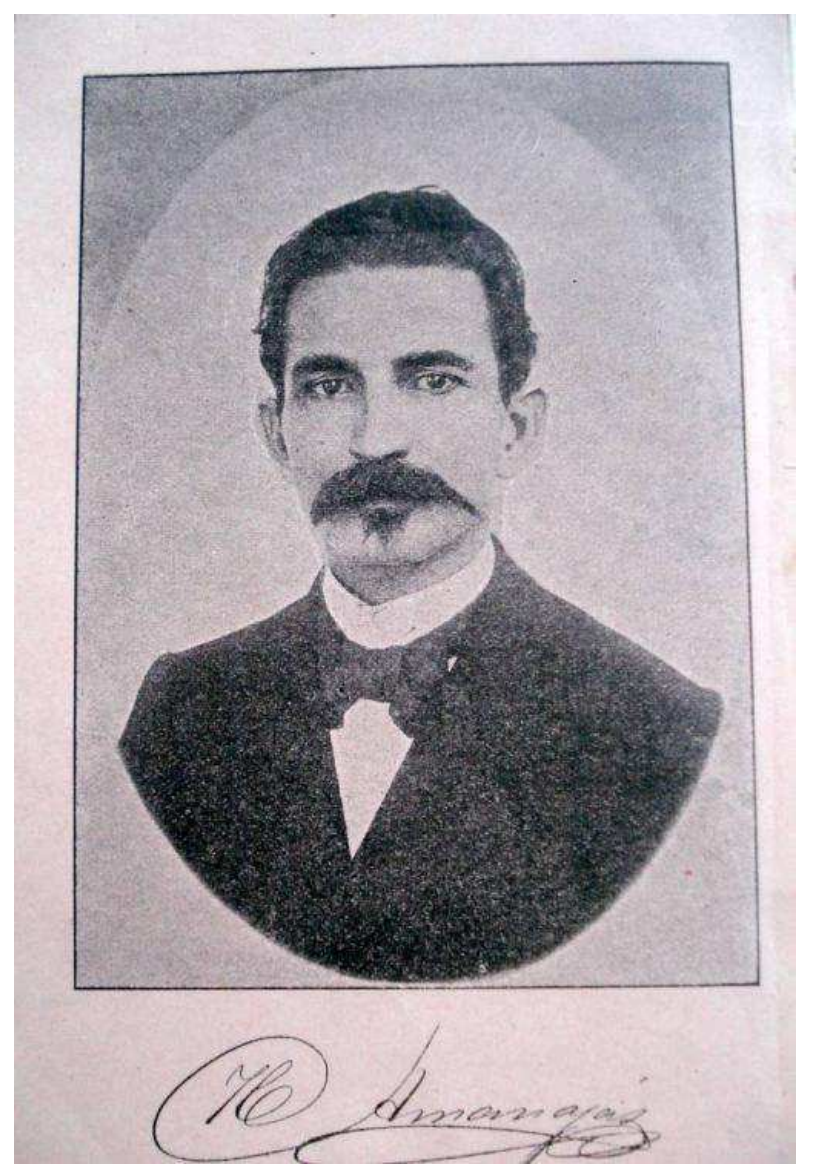

Figura 1- Hygino Amanajás.

Fonte - Dados da pesquisa.

Hygino Amanajás nasceu em 15/05/1852 na antiga Freguesia de Nossa Senhora da Conceição de Abaeté, hoje cidade de Abaetetuba, na localidade Rio Maracapucu, no Estado do Pará, faleceu em 17/01/1921. Estudou o primário em sua cidade natal e fez o secundário no Seminário Episcopal, sob a responsabilidade do sacerdote D. Antonio de Macêdo Costa. Ainda estudante, já colaborava no semanário Estrella do Norte. Foi jornalista (um dos fundadores do jornal $O$ Abaeteense e seu diretor por 10 anos e jornalista em Belém/Pará), advogado, escritor (escreveu diversas obras), procurador de Abaeté, deputado da Assembleia Legislativa por 3 mandatos sucessivos, foi o $1^{\circ}$ secretário dessa casa em 1886 , iniciou no $1^{\circ}$ mandato do Governador Lauro Sodré até a proclamação da República, no governo do Dr. João Coelho, e o $1^{\circ}$ diretor da Imprensa Oficial do Estado por 26 anos (11/6/1891-

\footnotetext{
${ }^{9}$ Os dados apresentados neste texto foram coletados em Cardoso (1915); Blog do Rocha Disponível em: <http://ademirhelenorocha.blogspot.com.br/2012> Acesso em: 10 abr. 2012; Grande Enciclopédia da Amazônia e Enciclopédia de Literatura Brasileira (1968).
} 
26/11/1917). Colaborador de diversos periódicos paraenses. Publicou livros que foram utilizados em escolas paraenses e em outros Estados, dentre esses, estão Contos e Lendas Paraenses, Noções de Educação Civica e Alma e Coração.

Hygino Amanajás participou ativamente da imprensa republicana, onde, como colaborador em alguns periódicos e diretor da Imprensa Oficial, escreveu, defendeu e propôs medidas relativas às questões sociais e educacionais.

É lembrado por muitos paraenses como o autor do projeto responsável pela adoção da bandeira do Estado do Pará. Esse projeto foi aprovado na Câmara dos Deputados após sua terceira submissão, isso porque o Senado paraense não tinha aprovado. Inicialmente, o pretexto para o indeferimento do projeto residia no fato de que o município de Belém já adotava essa bandeira, outro argumento frágil era que o Estado não podia ter bandeira própria. Essas justificativas foram superadas pela defesa realizada por Hygino Amanajás, autor do projeto. Esse embate em relação à adoção de uma bandeira é compreensível, uma vez que esse é um símbolo importante na construção e manutenção da legitimação de um regime político.

Hygino Amanajás, adepto aos ideais republicanos, acreditava que seria, sobretudo, por meio da educação e da conscientização do povo que o país poderia se desenvolver, via na instrução da população a garantia de acesso ao progresso. Logo após o advento da República, a educação foi tomada como instrumento de consolidação do novo regime político e de manutenção da ordem social. Ao visar contribuir com a formação exigida para o novo cidadão almejado pela República, escreveu os livros Noções de Educação Civica e Alma e Coração. No prefácio do livro Noções de Educação Civica, tem-se indícios sobre a percepção do autor em relação à educação,

\footnotetext{
Venho dar-vos algumas noções dos vossos direitos e deveres como futuros cidadãos, que sereis em breve, quando tiverdes ultimado os vossos estudos.

Para a felicidade e o progresso de um paiz só podem concorrer a instrucção e a educação civica e moral de seus filhos; uma sem a outra nada póde fazer, porque ellas se completam e se auxiliam.

Um paiz será tanto mais respeitado e prospero, quanto os cidadãos que o occuparem forem instruidos e preparados no conhecimento, não só das sciencias e das artes, mas tambem dos direitos e deveres (AMANAJÁS, 1898, Prefácio).
}

No processo de produção de um livro, encontram-se inseridos protocolos de leitura ${ }^{10}$ organizados em dois conjuntos de dispositivos distintos que, ao longo do processo, interagemse, complementam-se e acabam por guiar o leitor para uma leitura autorizada da obra. Esses

${ }^{10}$ Sobre protocolos de leitura ver CHARTIER(1998). 
dois conjuntos são constituídos por: procedimentos de produção do texto e de produção de livros.

Os procedimentos de produção do texto estão diretamente ligados à elaboração do texto são "senhas, explícitas ou implícitas, que um autor inscreve em sua obra a fim de produzir uma leitura correta dela, ou seja, aquela que estará de acordo com sua intenção" (CHARTIER, 1998, p. 95). No livro Noções de Educação Civica, identificou-se vestígios desses procedimentos no prefácio intitulado Ao Leitor, quando o autor comenta:

\begin{abstract}
Impressionado pela ignorancia dos meninos, que frequentam as nossas escolas, no que diz respeito aos seus deveres de cidadãos da patria, resolvi escrever este desprentencioso trabalho, em linguagem simples, e ao alcance da comprehensão de creanças, persuadido de que assim presto algum serviço aos meus conterraneos (AMANAJÁS, 1898, Prefácio, Ao Leitor).
\end{abstract}

Nesse trecho, o autor orienta sobre o tipo de leitura que é oferecida em sua obra e quem estaria autorizado a realizá-la. Aponta elementos que permitem a identificação do leitor, tais como: o tipo de linguagem utilizada, os conteúdos abordados que estariam ligados à concepção de pátria. Em que medida esse livro era "despretencioso" como apresentado pelo autor? Quais serviços o autor pretendia prestar aos conterrâneos ao publicar essa obra?

Em relação aos procedimentos de produção de livros, que são aqueles que estão diretamente ligados à impressão do livro, "é composto pelas próprias formas tipográficas: a disposição e a divisão do texto, sua tipografia, sua ilustração" (CHARTIER, 1998, p. 95). Tem-se por hipótese que Hygino Amanajás participou ativamente no desenvolvimento desses procedimentos por exercer o cargo de diretor da Imprensa Oficial, lugar onde eram publicados livros escolares. Já que esses procedimentos consistiam, basicamente, na organização dos conteúdos, na disposição dos elementos textuais e pré-textuais, na apresentação das páginas, na escolha do papel, etc. e estavam ligados diretamente ao processo de editoração.

$\mathrm{O}$ editor ${ }^{11}$ é o responsável por dar forma ao texto, por seu aspecto visual; cabia-lhe a tarefa de tornar o produto mais atraente para o seu consumidor, o leitor. Além dessas atribuições, Bragança (2005, p. 222) pontua que: “[...] insere implicitamente como encargo do editor a publicação, não apenas no sentido de dar à luz o livro impresso, mas na ação de tornálo conhecido, isto é, difundido, distribuído conhecido e lido". No período investigado, era também do autor a tarefa de divulgar a obra.

\footnotetext{
11 Segundo Bragança (2005), a palavra "editor", de origem latina, indica dois movimentos "dar à luz" e "publicar".
} 


\section{OS LIVROS NOÇÕES DE EDUCAÇÃO CIVICA E ALMA E CORAÇÃO: BREVE COMPARAÇÃO}

$\mathrm{Na}$ folha de rosto do livro Noções de Educação Civica o autor cita Castilho, "O que pede o espírito dos meninos? Noções claras, legitimamente dedusidas dêsde o mais simples até o mais complexo". Nessa citação, pode-se identificar indícios de aspectos vinculados ao positivismo, o que sugere a simpatia do autor, Hygino Amanajás, por essa teoria. De certa forma, sugere, ainda, preocupação com a realidade educacional das crianças e com uma possível tentativa de adequação da sequência pedagógica dos conteúdos a serem ensinados.

O livro Noções de Educação Civica foi utilizado neste trabalho com o intuito de contrapor ao livro Alma e Coração, para que fossem identificados elementos semelhantes e diferentes capazes de sugerir em que medida a obra Coração de Edmundo de Amicis serviu de inspiração ao autor Hygino Amanajás. A primeira obra foi publicada em 1898, no prefácio desse livro, o autor fez referência ao livro Coração, para indicar uma lacuna no que diz respeito à inexistência de livros escolares direcionados à formação de crianças, enquanto futuros cidadãos republicanos. "Nenhum livro temos neste genero: o Coração de Amicis, que se usa nas escolas, é um bellisimo livro; mas escripto para italianos e talvez em linguagem um pouco elevada para quem começa apprender" (AMANAJÁS, 1898, Prefácio, Ao Leitor).

Esse comentário evidencia a utilização do livro Coração em escolas paraenses e sinaliza uma intimidade entre o autor Hygino Amanajás e essa obra. Ao expor sobre o nível da linguagem veiculada no Coração, este autor deixa transparecer indícios que sugerem que ele detinha um conhecimento aprofundado sobre o mesmo, pois esse tipo de informação dificilmente é apreendido em uma leitura breve. Acredita-se que, a partir da constatação da inexistência de textos nacionais de cunho patriótico nas escolas primárias, o autor tenha empreendido esforços e escrito o livro Alma e Coração. 


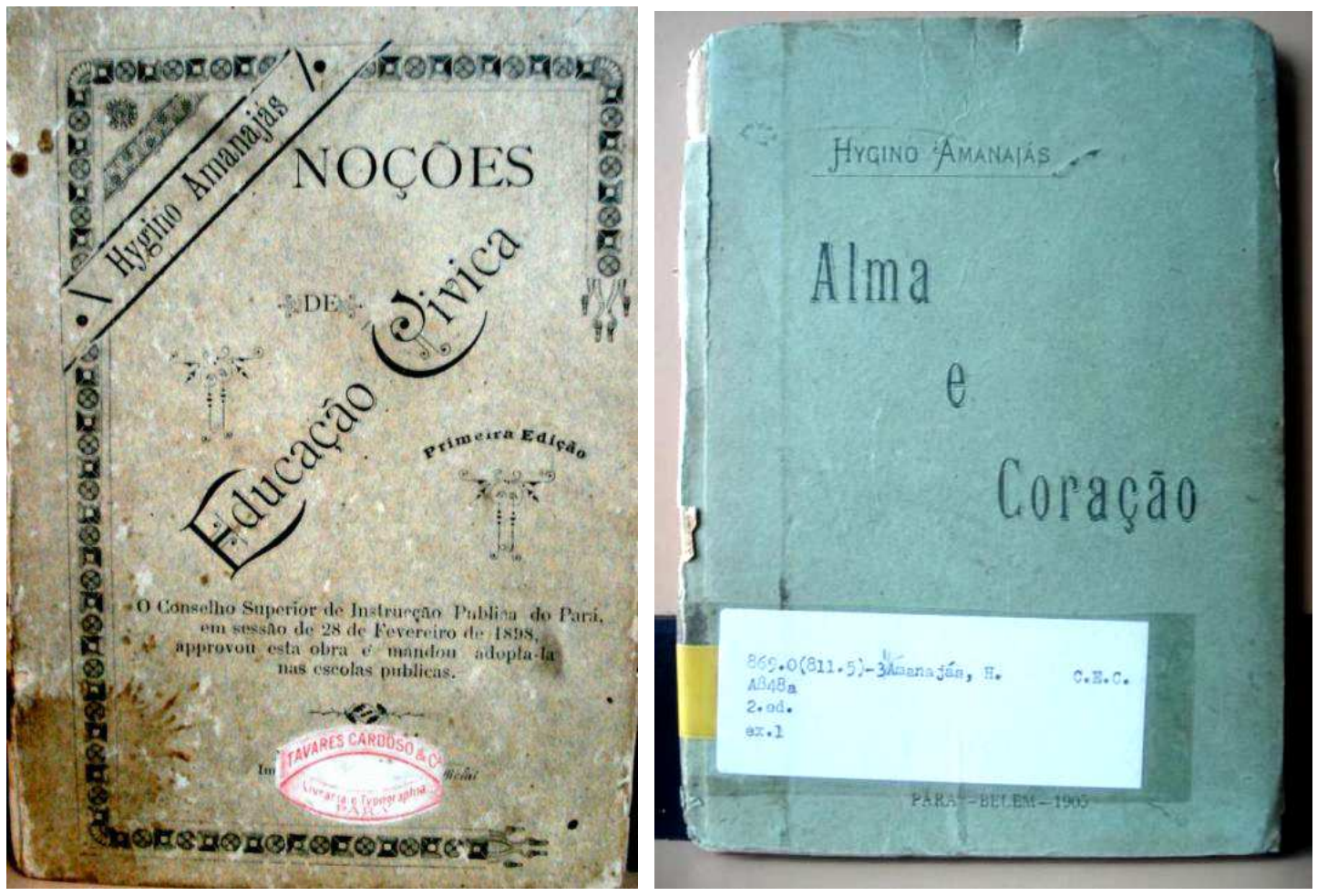

Figura 2 - Capas dos livros Noções de Educação Civica e Alma e Coração.

Fonte - Dados da pesquisa.

A Capa adotada para a obra Noções de Educação Civica é bem diferente da Capa do livro Alma e Coração, que se constitui basicamente do título da obra e do nome do autor, é toda verde-clara, com o nome do autor (em caixa alta) e o título (em negrito) organizado em forma de cascata. Que coincidentemente lembra a Capa do Coração. Após ter conhecimento dos comentários sobre a escassez de obras escolares nacionais que atendessem à demanda da formação da criança patriota, tem-se por hipótese que a cor utilizada na Capa do livro Alma e Coração está relacionada ao sentimento de esperança que essa obra poderia, naquele contexto, representar ao ensino primário paraense.

O sumário é outro componente do livro Noções de Educação Civica que evidencia o distanciamento deste com o livro Alma e Coração.

\section{Quadro 1 - Sumário do livro Noções de Educação Civica.}

\begin{tabular}{|l|l|}
\hline Títulos & Páginas \\
\hline APPOVAÇAO N 40 & ----- \\
\hline PARECER & ----- \\
\hline AO LEITOR & ---- \\
\hline MEUS MENINOS & ---- \\
\hline A PATRIA & PAG. 1 \\
\hline OS SIMBOLOS DA PATRIA A BANDEIRA NACIONAL & PAG. 5 \\
\hline
\end{tabular}




\begin{tabular}{|c|c|}
\hline A BANDEIRA DO PARA & PAG. 9 \\
\hline O HYNO NACIONAL & PAG. 13 \\
\hline A NAÇÃO BRASILEIRA & PAG. 16 \\
\hline CONSTITUIÇÃO POLITICA DO BRASIL & PAG. 22 \\
\hline CONSTITUIÇÃO PARAENSE & PAG. 26 \\
\hline GOVERNO DO PAÍS & PAG. 28 \\
\hline O PODER LEGISLATIVO & $P A G .32$ \\
\hline O PODER EXECUTIVO & PAG. 37 \\
\hline O GOVERNO ESTADUAL & PAG. 44 \\
\hline OS GOVERNADORES DO PARÁ & PAG. 50 \\
\hline O PODER JUDICIARO & PAG. 57 \\
\hline GOVERNO DO MUNICIPIO & PAG. 66 \\
\hline ATTRIBUIÇÕES DO CONSELHO MUNICIPAL & PAG.68 \\
\hline ATTRIBUIÇÕES DO INTENDENTE & PAG. 71 \\
\hline DIREITO DOS CIDADAOS & PAG. 77 \\
\hline A POLITICA & PAG. 82 \\
\hline DIREITO DE VOTO ELEIÇÃO & PAG. 87 \\
\hline DEVERES SERVIÇO MILITAR - JURY & PAG. 90 \\
\hline REGISTRO CIVIL NASCIMENTOS E OBITOS & PAG.94 \\
\hline CASAMENTO CIVIL & PAG. 102 \\
\hline DEVERES DA MULHER PARA COM A PATRIA & PAG. 110 \\
\hline HINO A PATRIA & PAG. 113 \\
\hline BRAZÃO D'ARMASBRAZÃO D'ARMAS DE SANTA MARIA DE BELÉM & PAG. 116 \\
\hline NOTA FINAL (MEMBROS DO CLUBE REPUBLICANO PARAENSE) & PAG. 118-120 \\
\hline
\end{tabular}

Fonte - Dados da pesquisa.

Ao analisar o sumário do livro Noções de Educação Civica, pode-se inferir que, de acordo com os títulos, os textos privilegiavam temáticas voltadas aos elementos constitutivos da nação: a pátria, os símbolos nacionais, o constitucionalismo, os direitos e deveres do cidadão. E são apresentados no gênero textual explicativo. Já o livro Alma e Coração, além de ter seus textos no gênero textual epistolar, o que o aproxima mais do livro Coração, cujo gênero textual adotado é o diário, tem ampliadas as temáticas exploradas. Como apontado no parecer do Conselho Superior de Instrução Pública, o livro Alma e Coração adota o mesmo plano do Coração, traz em seu conteúdo lições que apregoam valores cívicos e patrióticos e, ainda, valores como obediência, respeito, carinho, amor, bondade para com os menos afortunados, importância aos estudos e ao trabalho, controle dos pensamentos e dos atos reconhecidos como inconvenientes. Por tudo isso, considera-se o livro Alma e Coração um Coração brasileiro. 


\section{ALMA E CORAÇÃO: ALGUNS ASPECTOS}

O livro Alma e Coração teve sua $1^{\text {a }}$ edição publicada em Belém, pela Imprensa Oficial, no ano de 1900. Neste trabalho, utilizou-se um exemplar xerografado da $5^{\text {a }}$ edição, publicado em 1905, pela Imprensa Oficial do Estado do Pará.

Em relação ao processo de divulgação desse livro escolar, trabalhou-se com dados referentes à $1^{\mathrm{a}}$ edição. Esses dados evidenciaram que como estratégia de divulgação dessa obra, adotou-se a publicação de anúncios no jornal Diário Oficial do Estado do Pará e na revista A Escola - Revista Official de Ensino. Ambos editados pela Imprensa Oficial em Belém.

O anúncio com a divulgação do livro Alma e Coração foi publicado no Diário Oficial do Estado do Pará, na seção dos avisos particulares, dezesseis vezes, entre 13 de setembro e 09 de outubro de 1900. Tem-se por hipótese de que a recorrência da divulgação do livro Alma e Coração, no Diário Oficial do Estado do Pará, esteve atrelada ao fato do seu autor encontra-se na direção dessa instituição. Essa hipótese foi reforçada na medida em que, ao se pesquisar os exemplares desse periódico, publicados no espaço de tempo entre 1900 a 1907, foram visualizados anúncios com a divulgação de outras obras didáticas. No entanto, a quantidade de anúncios publicados era bem menor, não ultrapassava a quatro, com uma alternância maior em relação ao período publicado, ou seja, um anúncio publicado a cada semana. 


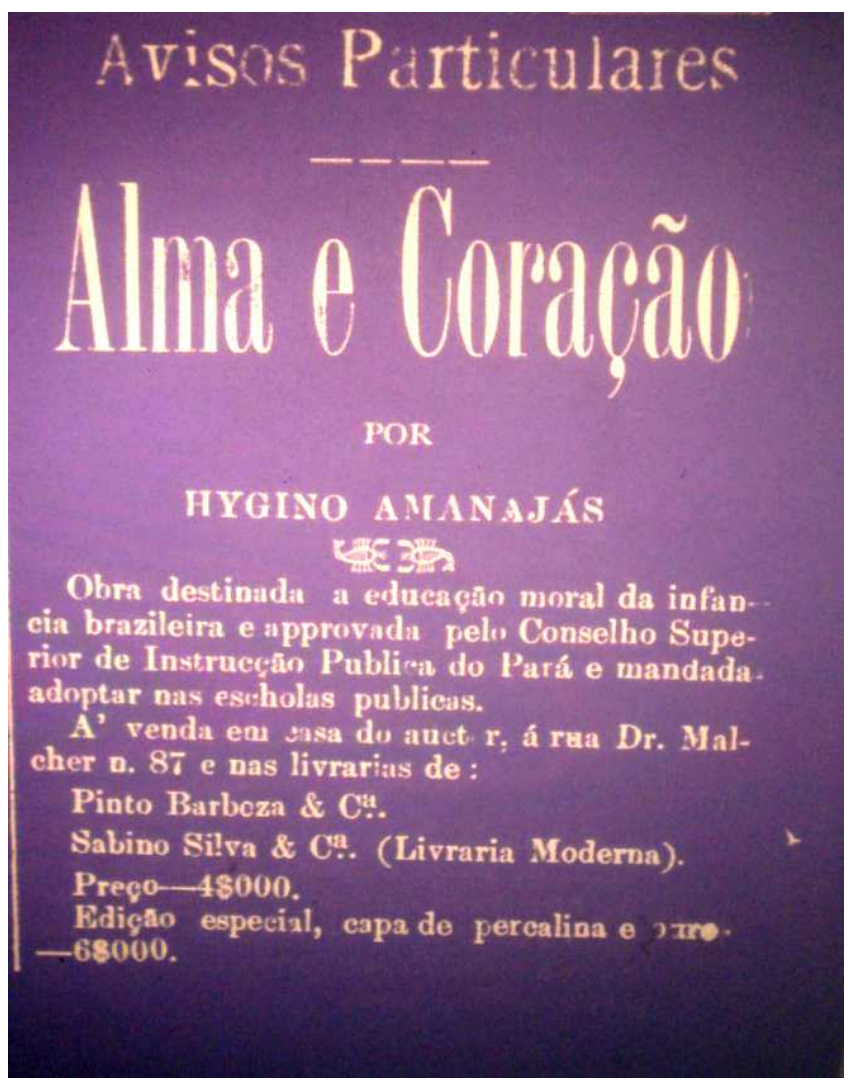

Figura 3 - Anúncio publicitário do livro Alma e Coração.

Fonte: Diário Oficial do Estado do Pará de 13 de setembro de 1900.

No anúncio, apresentado na figura acima, consta indícios sobre a obra e sua materialidade. Ao divulgar o público para o qual a obra era destinada, percebe-se a consonância com o projeto educativo da época, em que a educação moral das crianças era considerada um dispositivo capaz de contribuir com a unificação nacional apregoada pelos republicanos. No final do século XIX e início do século XX, a aprovação pelos Conselhos Superiores de Instrução Publica dos Estados era, em muitos Estados, condição para que o livro pudesse ser utilizado em escolas públicas.

As experiências de Hygino Amanajás no campo educacional, intelectual e seus contatos políticos contribuíam para a aprovação de suas obras didáticas. Para Bittencourt (2004, p. 482), “a concepção de livro didático e a sua destinação eram determinações quase exclusivas do poder político educacional, que procurava, no grupo da elite intelectual, apoio para a produção desse tipo de literatura". Pode-se considerar Hygino Amanajás um desses intelectuais, uma vez que, sua trajetória profissional, descrita anteriormente, permite inferir que ele pensava e problematizava a educação naquele período.

Outro dado interessante fornecido pelo anúncio é o local de venda do livro. A residência do autor como local de referência para a venda da obra retrata uma estratégia 
comum ao período estudado. A divulgação e venda das obras, principalmente das primeiras edições, geralmente eram realizadas pelos próprios autores aos diretores e professores das escolas.

As empresas Pinto Barboza \& $C^{a}$ e Sabino Silva \& C (Livraria Moderna) figuravam entre as livrarias, categoria empresarial, que simbolicamente representavam a civilidade e modernidade possibilitadas pela época áurea da borracha. O comércio livreiro de Belém apresentava "relativa importância na última parte do século XIX, pode ser avaliada pelo catálogo da Garraux de 1883, onde os colofãos de Belém, em quantidade, vinham logo após os do Rio de Janeiro, do maranhão (§44), de São Paulo (§97), Pernambuco e Minas Gerais (§24)" (HALLEWELL 2005, p. 192).

Outro aspecto da materialidade da obra contemplado no anúncio diz respeito ao tipo de capa utilizada, que seguramente refletiu no preço do livro. A edição especial era de percalina $^{12}$ e ouro e custava $6 \$ 000$, já a edição comum custava $4 \$ 000$. Sabe-se que "a capa funciona como uma arma de sedução para que o livro seja aberto e/ou comprado" (HASLAM, 2007, p. 160). Entretanto, o referido material é uma incógnita, uma vez que, não foi encontrado exemplar da $1^{\mathrm{a}}$ edição dessa obra.

Ao utilizar como estratégia de marketing e com o objetivo de difundir sua obra no campo educacional, o autor enviou à revista $A$ Escola $^{13}$ um exemplar do seu livro conforme a nota que faz a divulgação do livro Alma e Coração em 30 de setembro de 1900 e a resenha publicada na edição de outubro de 1900.

Acredita-se que a resenha supracitada, tenha cumprido seus objetivos de: apresentar, em sua totalidade, a obra Alma e Coração e servir de elemento persuasivo a sua aquisição. Tem-se por hipótese que, devido à qualidade do texto apresentado na resenha e o público ao qual era destinada a revista $A$ Escola, essa estratégia de divulgação do livro tenha contribuído para sua adoção em escolas paraenses.

O autor Hygino Amanajás, no prefácio da $5^{a}$ edição, revela indícios sobre a ampla aceitação de sua obra tanto na família quanto na escola, comenta ainda que, a $1^{\text {a }}$ edição, com tiragem de cinco mil exemplares, teria se esgotado em três anos. $\mathrm{O}$ reconhecimento desse livro, no contexto social e escolar, é apontado pelo próprio autor quando declara que: "De

\footnotetext{
12 Tecido utilizado para revestir a capa.

${ }^{13}$ A Escola era a revista oficial de ensino, com publicação mensal, foi fundada pelo Diretor Geral da Instrução Publica, Vigilio Cardoso de Oliveira, que também detinha o cargo de redator-chefe. Tal impresso constituía um importante instrumento de divulgação das novidades instituídas pelo governo para os professores. Era enviada às escolas do Estado do Pará.
} 
professores e particulares recebi congratulações animadoras, que me deram coragem, para fazer uma segunda tiragem, corrigido o texto, libertando-o dos erros que escaparam na primeira, e modificando-o ou ampliando-o, onde julguei necessario" (AMANAJÁS, 1905, $\mathrm{s} / \mathrm{p})$.

No que tange ao processo de circulação do livro Alma e Coração, dados coletados em fontes como a Revista do Ensino ${ }^{14}$, do Estado de Minas Gerais, confirmam sua ampla circulação. E permite afirmar que, além da circulação em escolas no Estado do Pará, esse livro também circulou em escolas do Estado de Minas Gerais.

$\mathrm{Na}$ Revista do Ensino, $\mathrm{n}^{\circ} 9$ (p. 261, 1925), tem-se publicada uma listagem com os títulos dos livros existentes na sala de leitura "Dr. Sandoval Azevedo", do Grupo Escolar Barão do Rio Branco, no ano de 1925. Na seção de livros educativos e instrutivos, encontramse vários títulos de livros, dentre eles, o Alma e Coração.

Acredita-se que o livro Alma e Coração encontrava-se nessa seção dessa biblioteca escolar, por apresentar um caráter moralizante, típico dos livros de leitura utilizados em escolas primárias da época, que produziam, em suas páginas, ideias e sentimentos relacionados aos valores morais e cívicos. Nessa perspectiva, reconhece-se os livros de leitura como:

Depositário de um conteúdo educativo, o manual tem antes de mais nada, o papel de transmitir às jovens gerações os saberes, as habilidades (mesmo o saber "ser") os quais em uma dada área e a um dado momento, são julgados indispensáveis à sociedade para perpetuar-se (CHOPPIN, 2002, p. 14).

Nas primeiras páginas do livro Alma e Coração, o Parecer elaborado por uma comissão representante do Conselho Superior de Instrução Pública dá voz a um conjunto de justificativas téorico-metodológicas que favorecem a aprovação, por essa comissão, da obra.

Este livro é escripto segundo o plano do Coração de Amicis, como confessa o proprio autor no prefacio. A originalidade está por tanto somente na escolha dos assumptos e no modo de os expôr e desenvolver.

Ora os assumptos são excellentes, e exposição muito bem trabalhada.

$\mathrm{O}$ autor trata ahi de espertar no espirito das creanças, por meio de agradeaveis prelecções: a crença na existencia de Deus e na immortalidade da alma, o amor filial, o amor fraterno, a perseverança no trabalho, a humildade, o amor para com Deus e para com a patria, os sentimentos de caridade, etc.

Especialisaremos os artigos de commemoração aos grandes dias da patria, muito bem escriptos.

\footnotetext{
${ }^{14}$ A Revista do Ensino - publicada pela Diretoria de Instrução Pública, constituía um importante instrumento de divulgação das novidades instituídas pelo governo para os professores. Era enviada às escolas em Minas Gerais. Exemplares dessa revista podem ser encontrados para consulta na biblioteca do Centro de Referência do Professor de Belo Horizonte.
} 
Há tambem algumas descripções dignas de nota; e o maior mérito d'ellas é tratar de cousas nossas, de factos passados entre nós, e que o menino com facilidade comprehende. (AMANAJÁS, 1905, s/p).

As considerações sobre a obra, apresentadas no Parecer, chamam atenção para sua originalidade e revelam a sua relevância por possibilitar o preenchimento do vazio de livros que contemplassem a realidade paraense. É destacada a primazia empregada na escolha e adequação dos conteúdos às necessidades demandadas para a formação do cidadão republicano. Segundo Bittencourt (1993, p. 154):

\begin{abstract}
O conceito de cidadania, criado com o auxílio dos estudos de História, serviria para situar cada indivíduo em seu lugar na sociedade: cabia ao político cuidar da política e ao trabalhador comum restava o direito de votar e de trabalhar dentro da ordem institucional. Os efeitos dos "grandes homens", de seres predestinados, haviam criado a nação e representantes destas mesmas elites cuidariam de levar a nação ao seu destino.
\end{abstract}

Dessa forma, esse livro atenderia ao objetivo de contribuir na construção e manutenção de um imaginário coletivo, que reforçava a existência de uma ordem social estruturada que deveria ser seguida sem questionamentos.

A preocupação com valores morais e cívicos permeia toda a obra. A religiosidade também é um tema apresentado com intensidade nesse livro. Por um lado, essa intensidade sugere a existência de um paradoxo, no diz respeito ao seu contexto de produção, naquela época a sociedade se estabelecia como laica. Os livros de leitura eram considerados mecanismos viabilizadores das luzes da ciência, da civilidade e do patriotismo. Por outro, permite considerar que o autor trabalhou na perspectiva da civilidade cristã ${ }^{15}$. As virtudes e o combate aos vícios, apontados pelo autor em seu livro, fortificariam a ação republicana.

Hygino Amanajás nas páginas de seu livro Alma e Coração deixa entrever aspectos que valorizam a religiosidade. Isto é, no reconhecimento da existência de um Ser supremo, no entendimento de que a vida dos homens é moldada pelos desígnios de Deus, com ensinamentos de caridade, fé e bondade ou até mesmo com a vinculação da religiosidade ao patriotismo. Como explicitados nos exemplos a seguir:

Só um Ser infinitamente poderoso fôra capaz de produzir o universo; só um Ser extremamente bondoso poderia crear tudo o nos cerca para nossa utilidade e recreio; só Deus, - a força e intelligencia supremas - podería crear o homem, esse mundo abreviado, organização excepcional, dotado de alma, isto é, - espirito - e de corpo ou - materia, - tão intimamente unidos, produzindo o phenomeno da vida e da morte. (AMANAJÁS, 1905, p. 36).

\footnotetext{
${ }^{15}$ Em relação à civilidade cristã, Chartier (2004, p. 64.Grifo do autor) explicita: “A civilidade é, então ao mesmo tempo, honestidade e piedade e abrange tanto 'a glória de Deus e salvação' como a conveniência social”.
} 
E deveis amal-a ainda mais, se é possivel; porque Deus vos deu por patria esta esplendida terra da luz e da fecundidade, que se chama Brazil, permitindo que a forma do seu governo fosse a mais liberal e mais digna do homem civilizado. (AMANAJÁS, 1905, p. 22).

A religiosidade entremeia quase todas as narrativas, torna-se, de certa forma, pano de fundo no desenrolar da história de Ernesto $^{16}$. Ela ocupa um lugar de destaque nessa obra. Mesmo quando o assunto poderia ser abordado de maneira cientifica, o autor optou por explaná-lo via religiosidade. Como exemplo, tem-se o relato de Ernesto sobre uma aula: “Hoje, disse-nos, falaremos do homem, meus amiguinhos, do homem, que é a obra mais perfeita do Creador" (AMANAJÁS, 1905, p. 46).

Alguns textos são compostos por elementos que despertam o civismo e a religiosidade. "Só há uma soberania, e essa é a da lei, emandada do proprio povo. Amai a Republica; porque amando-a engrandecereis a vossa patria, e a patria deve ser objecto do vosso maior amor, depois de Deus" (AMANAJÁS, 1905, p. 22). Estes sugerem que o sentimento patriótico é necessário e importante, porém a religiosidade se encontra acima de tudo que é terreno.

Em outra aula, o professor aconselha seus alunos: "Conservai-vos dignos de vós mesmos; honrai a vossa qualidade de seres racionaes, e provai, pelos vossos actos de moralidade e religião, que abaixo de Deus, no mundo, está o homem" (AMANAJÁS, 1905, p.30). Essa religiosidade propagada nesse livro contribuía para legitimar valores cristãos universais.

Em algumas narrativas, a religiosidade aparece de forma naturalizada, é aludida em ações cotidianas. Como quando Ernesto tenta ajudar o seu amigo Luciano: "- Mas, isso é também orgulho, Luciano, e no entanto Deus sabe que não te quero ofender. Aceita esta bolsa, meu amigo; ella contém muito pouco para o que necessitas...” (AMANAJÁS, 1905, p. 94). Assim, a religiosidade se fez presente em várias narrativas.

Em seu livro, Alma e Coração, Hygino Amanajás agregou o valor religioso aos conteúdos trabalhados na escola, logo forneceu pistas sobre sua posição em relação à religiosidade no ensino.

Outro aspecto interessante, trabalhado nessa obra, está vinculado às evidências de singularidades regionais, como apontado no Parecer elaborado pela comissão representante do Conselho Superior de Instrução Pública, o que permitiria ao leitor paraense uma maior aproximação com a obra.

\footnotetext{
${ }^{16}$ Protagonista do livro Alma e Coração.
} 
Além da divulgação de heróis e paraenses ilustres, o autor prioriza situações que possibilitam a identificação do leitor com o texto. Uma dessas situações é a descrição que Ernesto faz da cidade de Belém na carta que envia à mãe:

A cidade, que me havieis descripto, foi absorvida por uma outra, mais enfeitada pelo progresso. D'aquella que conhecieis, bem pouca cousa resta.

As praças da Independencia, Republica, Frei Caetano Brandão, Rio branco e Baptista Campos estão todas ajardinadas. (AMANAJÁS, 1905, p. 8).

Em outras narrativas, ao mesmo tempo, quando explicita valores republicanos, o autor busca uma aproximação do conteúdo trabalhado com a realidade local. Ao escrever para a mãe relatando a aula que tivera sobre a data festiva referente à promulgação da lei áurea, Ernesto tece o seguinte comentário:

É certo que entre nós, os paraenses, o escravo foi menos infeliz. Fazia parte da familia, era estimado e recebia, às vezes, instrucção e educação; mas não era livre, não era homem: era um objecto de seu dono, uma cousa que representava apenas um valor monetario, sujeito ás transacções commerciaes, como uma mercadoria qualquer.

Abençoados os que tiveram a coragem de luctar com os preconceitos e o egoismo de muitos, para darem a carta de alforria aos captivos brazieliros. (AMANAJÁS, 1905, p. 68).

Por tudo que foi apresentado, considera-se que esse autor demonstrava uma preocupação em acompanhar a realidade educacional, isto é, as mudanças teóricas e metodológicas que ocorriam na tentativa de adequar da melhor forma suas obras ao público ao qual eram destinadas.

\section{REFERÊNCIAS}

AMANAJÁS, Hygino. Alma e Coração. Belém: Imprensa Oficial, 5. ed., 1905.

Noções de Educação Civica. Belém: Imprensa Oficial, 1898.

BITTENCOURT, Circe M. F. Autores e editores de compêndios e livros de leitura (18101910). São Paulo, Revista da Faculdade de Educação da USP, 30 (03): 475-491, set/dez. 2004.

Livro didático e conhecimento histórico: uma historia do saber escolar. Tese de Doutorado. Faculdade de Filosofia, Letras e Ciências Humanas. Universidade de São Paulo. São Paulo, 1993.

BRAGANÇA, Aníbal. Sobre o editor: notas para sua história. In: Em Questão, Porto Alegre, Rio Grande do Sul: v. 11, n 2, p. 219-237, Jul./Dez. 2005. 
CARDOSO, Firmo. Evolução da escola primaria no Pará. In: Moura, Ignacio (Org.). Annuario de Belém: em commemoração do seu tricentenário; historico, Litterario e Commercial. Imprensa Oficial, 1915.

CARVALHO, Marta M. C. de. Por uma história cultural dos saberes pedagógicos. In: CATANI, D. B.; SOUZA, C. P. (Org.). Práticas educativas, culturas escolares, profissão docente. São Paulo: Escrituras, 1998, p. 31-40.

CHARTIER, Roger. Do livro à Leitura. In: CHARTIER, Roger (Org.) Práticas da Leitura. Trad. Cristiane Nascimento. São Paulo: Estação Liberdade, 1998, p. 77-106.

Leituras e leitores na França do antigo Regime. Trad. Álvaro Lorencini. São Paulo: editora UNESP, 2004.

CHOPPIN, Alain. O historiador e o livro escolar. In: História da Educação/ASPHE (Associação Sul-rio-grandense de Pesquisadores em História da Educação) FaE/UFPEL, ${ }^{\circ}$ 11, abril 2002.

COELHO, Maricilde. A escola primária no Estado do Pará (1920-1940). Tese de Doutorado. Faculdade de Educação, Universidade de São Paulo. São Paulo, 2008.

HALLEWELL, Laurence. O livro no Brasil: sua história. Trad. Maria da Penha Villabolos, Lólio Lourenço de Oliveira e Geraldo Gerson de Souza. 2. ed. rev. ampl. São Paulo: Editora da Universidade de São Paulo, 2005.

HASLAM, Andrew. O livro e o design II: como criar e produzir livros. São Paulo: Rosari, 2007.

VEIGA, Cynthia Greive. Educação estética para o povo. In: LOPES, Eliane Marta Teixeira; Faria Filho, Luciano Mendes de; Vidal, Diana.500 anos de educação no Brasil. 2. ed. Belo Horizonte: Autêntica, 2000, p. 399-422. 